\title{
Thoracoscopic vagal-sparing esophagectomy and colonic interposition for caustic stricture
}

\author{
Deniz Tihan ${ }^{1,2}$, Tuğba Matlım³, Taylan Çelik ${ }^{4}$, Fatih Altıntoprak ${ }^{5}$ Oktar Asoğlu
}

\section{ABSTRACT}

\section{Cite this paper as:}

Tihan D, Matlım T, Celik T,

Altıntoprak F, Asoğlu 0..

Thoracoscopic vagal-sparing

esophagectomy and colonic

interposition for caustic

stricture. Turk J Surg 2018;

34: $53-56$.

'Department of General Surgery, Şevket Y.lmaz Research and Training Hospital, Bursa, Turkey

2Department of Anatomy, Uludağ University School of Medicine, Bursa, Turkey

${ }^{3}$ Department of General Surgery, Liv Hospital, İstanbul, Turkey

${ }^{4}$ Department of General Surgery, Antalya Ataturk State Hospital,

Antalya, Turkey

${ }^{5}$ Department of General Surgery, Sakarya University School of Medicine, Sakarya, Turkey

This study was presented at the $8^{\text {th }}$ National Congress of Endoscopic Laparoscopic Surgery 1-4 July 2007, Antalya, Turkey.

Address for Correspondence Deniz Tihan

e-mail: dtihan@yahoo.com

Received: 19.08.2015

Accepted: 28.11.2015

CCopyright 2018

by Turkish Surgical Association

Available online at

www.turkjsurg.com
Minimally invasive esophagectomy is an increasing trend in surgery. Thoracoscopic esophagectomy is applicable and an alternative procedure to conventional esophagectomy in patients especially with end-stage benign diseases like caustic stricture.

A 33-year-old female patient was admitted to the department of general surgery with dysphagia. The patient was suffering from caustic stricture due to ingestion of hydrochloric acid. A totally thoracoscopic and laparoscopic vagalsparing esophagectomy and colonic interposition was performed.

As a more physiologic alternative, vagal-sparing esophagectomy is the ideal operation for these patients.

Keywords: Causticesophageal stricture, esophagectomy, esophageal diseases, minimally invasive surgery, thoracoscopy, vagal nerve preservation

\section{INTRODUCTION}

The general intention of surgeons is to perform a standard transhiatal or transthoracic esophagectomy with colonic interposition or gastric pull-up procedure for benign end-stage and premalignant or in situ malignant lesions of the esophagus. During none of these operations, the standard preservation of paraesophageal vagal nerves is performed (1). According to the complex connections of vagal innervation, the complications of truncal vagotomy are, as well known, diarrhea, gastric stasis, dumping, early satiety, weight loss, and also cholelithiasis. Consequently, vagal-sparing esophagectomy (VSE) may avoid all these complications and might be considered as an attractive alternative to conventional esophagectomy.

Vagal-sparing esophagectomy was first described by Akiyama in 1982 (2); further, Collard et al. (3) and Banki et al. (1) performed successful esophageal stripping operation series with preservation of the vagal nerve. Regarding the literature, there are some other authors who have reported on the preservation of the vagal nerve during esophagectomy (4-6).

The common aim of all studies about vagal-sparing esophagectomy was to convince that esophagectomy might be the "gold standard" procedure for end-stage benign and early malign esophageal diseases if vagal nerves could be preserved during the operation (1). However, most authors do not favor preserving the vagi (7-9). Thus, in the literature, there are very few reports of esophagectomy with vagal preservation.

\section{CASE PRESENTATION}

A 33-year-old female patient was admitted to the department of general surgery with dysphagia. She had attempted suicide 1 year ago by ingesting of caustic substance (hydrochloric acid: $\mathrm{HCl}$ ). She had undergone several unsuccessful endoscopic dilatations. Her past medical history revealed epileptic seizures.

On admission, the blood pressure was $110 / 65 \mathrm{mmHg}$, heart beat rate was $92 \mathrm{beats} / \mathrm{min}$, and body temperature was $36.7^{\circ} \mathrm{C}$. Laboratory tests revealed the following: Hct: \%37.8, Hb: $12.9 \mathrm{~g} / \mathrm{dL}, \mathrm{WBC}: 8900 / \mu \mathrm{L}$, Plt: $385000 / \mu \mathrm{L}, \mathrm{BUN}$ : $10 \mathrm{mg} / \mathrm{dL}$, creatinine: $0.7 \mathrm{mg} / \mathrm{dL}$, blood glucose: $97 \mathrm{mg} / \mathrm{dL}, \mathrm{K}: 4.2 \mathrm{mEq} / \mathrm{L}, \mathrm{Na:} 139$ mEq/L, CA 19-9: 17.8, AFP: 2, CEA: 0.8, Ast: 16, ALT: 11, ALP: 116, GGT: 65, total bilirubin: 0.4, albumin: 4, International Normalized Ratio (INR): 1.00, ESR: 22 mm/h, and hsCRP: $6.0 \mathrm{mg} / \mathrm{l}$. Physical examination revealed burn scars in both her upper extremities. Chest radiography and echocardiography (ECG) at that time did not reveal any pathology. Upper endoscopy showed an intense fibrosis stenosis at the proximal esophagus, $15 \mathrm{~cm}$ from the teeth, impeding the progression of a 9-mm endoscope. Axial computed tomography (CT) scan of the thorax and abdomen was performed on the same day. CT scan showed a suspicious tracheoesophageal fistula at the arcus aorta level. 
No finding on behalf of a fistula but multiple strictures was noticed in esophageal fluoroscopic studies performed with a water-soluble oral radiocontrast material (Figure 1). The colonic vascular structure was evaluated by mesenteric angiography and no significant finding was noticed.

Pulmonary function studies were performed. The patient's respiratory reserve was found favorable. Patient was consulted with the neurology and psychiatry clinics. Psychiatry consultant diagnosed major depression with psychotic features. Thus, she was put on escitalopram (10 mg/d oral solution) and risperidone liquid ( $2 \mathrm{mg} / \mathrm{d}$ ). She was also put on valproic acid $(750 \mathrm{mg} / \mathrm{d}$ oral solution) as suggested by the neurologist and psychiatrist.

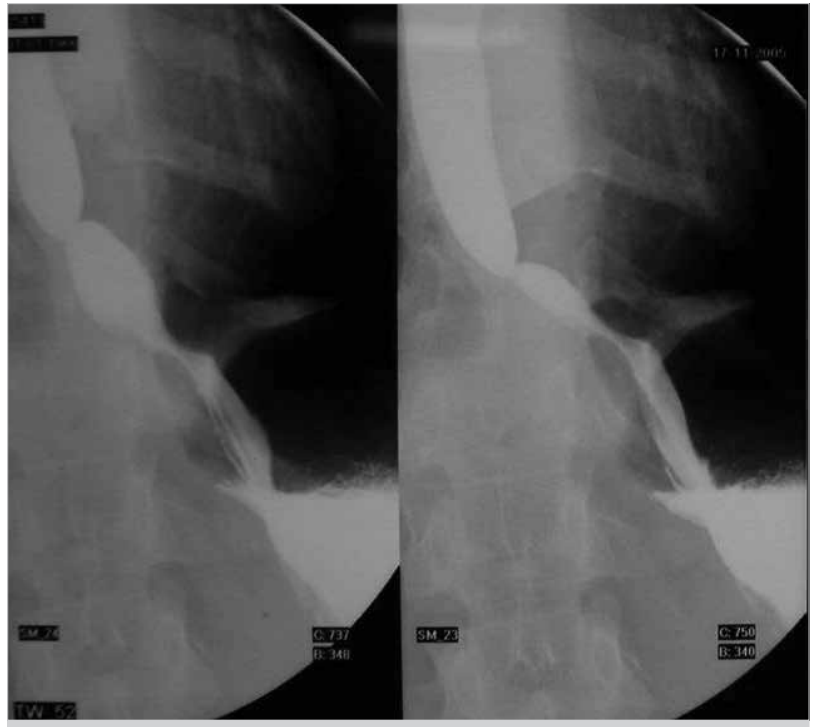

Figure 1. Multiple esophageal strictures on barium studies

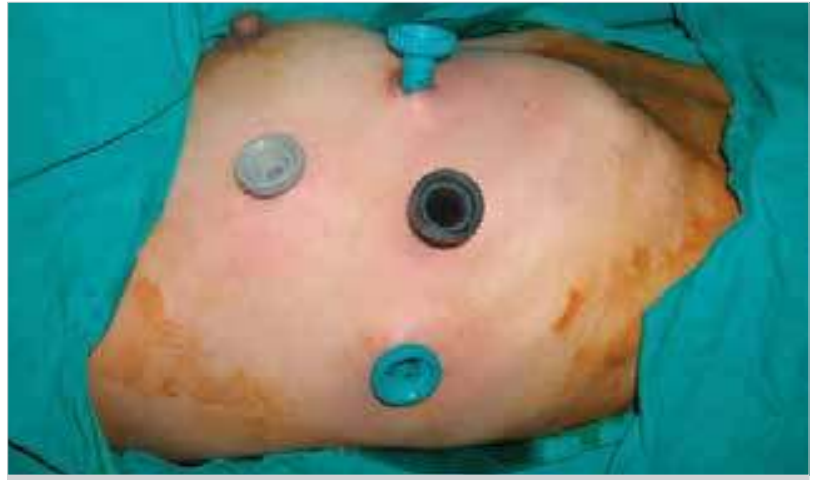

Figure2. Placement of the thoracoscopic trocars

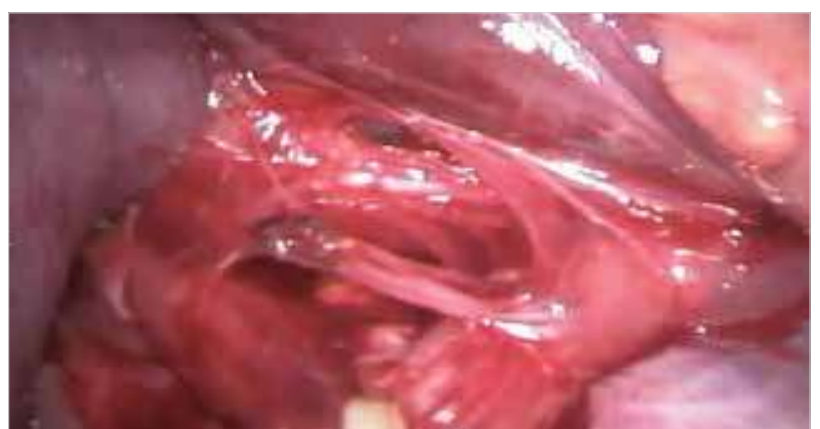

Figure 3. The identification of vagal nerves and traction of esophagus
Written informed consent was obtained from the patient and she was operated at the $10^{\text {th }}$ day of her administration. A thoracoscopic VSE and colonic interposition was carried out. First days of the postoperative period were uneventful. On the $2^{\text {nd }}$ postoperative day, $20 \%$ human albumin $(100 \mathrm{cc} / \mathrm{d})$ and total parenteral nutrition were initiated. The patient was allowed gradually to drink water on the $2^{\text {nd }}$ day and she was put on early liquid enteral nutrition on the $3^{\text {rd }}$ day of the surgery. Apical thorax tube and abdominal drain were withdrawn on the $4^{\text {th }}$ day. Unfortunately, on the night of the $7^{\text {th }}$ postoperative day, she had an unexpected cardiopulmonary arrest due to another suicide attempt by taking a box of warfarin sodium pills per os, probably acquired with the help from one of her family member, despite the frequent psychiatric consultations and 24-hstrict surveillance by nurses. She did not respond to CPR and died at the hospital.

\section{Surgical Tactic}

The surgical tactic consists of three main operations: thoracoscopy, laparotomy, and cervicotomy.

After the routine general anesthesia induction, the patient was selectively intubated with a double-ducted 7-F endobronchial tube and left lung was isolated. The prophylactic antibiotic combination (cefuroxime axetil $1500 \mathrm{mg}$ flacon IV+metronidazole $500 \mathrm{mg}$ flacon IV) was infused just after the induction. Then the patient was positioned in left lateral decubitus for optimum exposure of the upper portion of the mediastinum. The skin was cleaned with antiseptics and the area was covered with sterile scrubs.

\section{Thoracoscopy}

Four thoracoscopic ports introduced into the thorax were used for the thoracoscopic exploration and dissection: $4^{\text {th }}$ intercostal space on mid-axilla line, $5^{\text {th }}$ intercostal space on anterior-axilla line, $7^{\text {th }}$ intercostal space on mid-axilla line, and $8^{\text {th }}$ intercostal space on posterio-axilla line (Figure 2). With an endoscopic retractor, the right lung was moved to the medial portion of the right hemithorax. The mediastinal pleura was incised and an adequate exposure of the esophagus was obtained. Vagal nerves were identified and medially retracted and then the dissection of distal portion of esophagus was performed (Figure 3). According to the dissected portion of the esophagus, the surgical instruments and even the optics were transferred from one port to another. Identification of the azygos vein and its division were performed using the endoscopic vascular stapler device (Endo-Gia device; US Surgical, Norwalk, CT). The vagal nerves were freed from the muscular wall of the esophagus. The preservation of the nerves was the critical part of this procedure (Figure 4). The esophagus was dissected from the superior thoracic aperture to the hiatus, and 28 -and $30-\mathrm{F}$ thoracic catheters were placed and attached to an underwater-seal bottle without negative suction. The port sites were sutured. The thoracoscopic procedure time was about $2.5 \mathrm{~h}$.

\section{Laparotomy and cervicotomy}

After esophageal dissection, the two other main operations were performed in sequence, with colonic transposition and hypopharingocolonic anastomosis.

The patient was replaced in a supine position and the skin was prepared in the routine manner. Median incision was 
performed. The abdominal part of the vagal nerves was also preserved. The left colonic portion vascularized by the left colonic artery was prepared for the interposition. Left cervical incision was made through the skin and platysma muscle along the anterior border of the sternocleidomastoid muscle. Cervical esophagus was dissected by preserving the left recurrent nerve and vascular structures. Proximal part of the stomach was divided at the esophago cardiac junction. Esophagus specimen was withdrawn out by the cervical way (Figure 5). The transverse colon was placed in the retro gastric space and pulled-up through the mediastinal tunnel into the neck and hypopharingo colonic anastomosis were performed. The distal end of the colonic segment and proximal end of the stomach was anastomosed. A mediastinal drainage with a closed system was performed. Also, two silastic drains were placed for temporary drainage; one into the cervical space and the other into Douglas' space.

These two steps took approximately $4 \mathrm{~h}$. Even being submitted to single lung ventilation during surgery, respiratory parameters were unremarkable. After surgery, the patient was monitored in the intensive care unit on her first postoperative day. By thoracic drainage with closed system, the pulmonary expansion was restored in a short period.

\section{DISCUSSION}

Caustic substance ingestions can seriously damage the esophagus, stomach, and duodenum. The clinical presentation depends upon the type and concentration of the caustic material and the most common early complication is the perforation, which can be fatal. However, it is also very difficult to treat the long-term complications, especially the formation of esophageal strictures, which may even cause carcinomas. Corrosive strictures of the esophagus after the ingestion of caustic materials appear in up to $85 \%$ of the patients (7).

Prevention of stricture formation includes steroids, stenting, use of indwelling nasogastric tube, and early dilatation; even various immunomodulators have been used to prevent the

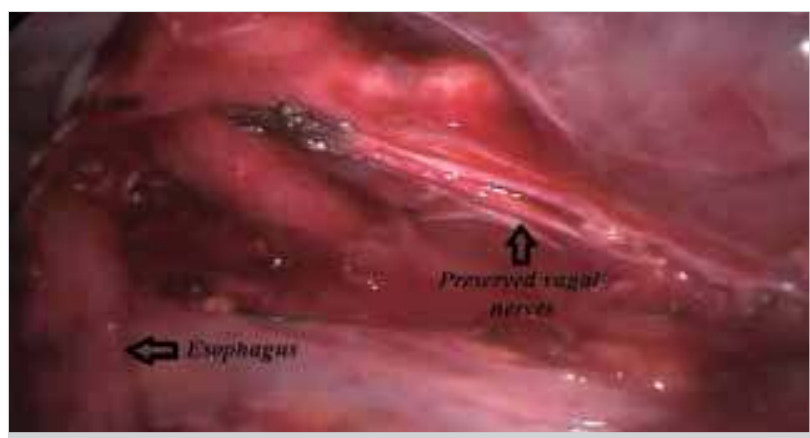

Figure 4. Bird's-eyeview of preserved vagal nerves

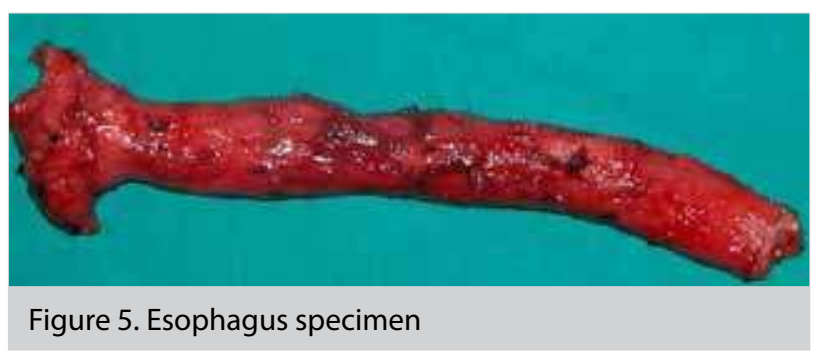

fibrosis $(10,11)$. However, the definitive treatment of caustic esophageal strictures is a reconstructive surgery. Traditional procedures for esophageal reconstruction are transhiatal or transthoracic esophagectomy with gastric pull-up or colonic interposition with interruption of vagal nerves. On the other hand, the sacrification of the vagi may result in many severe postoperative gastrointestinal complications such as diarrhea, gastric stasis, dumping, weight loss, and cholelithiasis.

Regarding the literature, Akiyama (2) is the first author who described esophageal stripping with preservation of the vagal nerves. Nevertheless, this technique did not achieve the deserved popularity and transhiatal esophagectomy with colonic interposition still remains the most favorite approach. Although esophageal stripping with preservation of the vagal nerves can be performed with a very small morbidity rate (12), surgeons are unwilling to perform VSE by stripping because the technique includes a blind dissection. Yet, we emphasize the importance of the necessity of the many communicant branches between the two vagi on the physiological vagal function. Chang and Jobe (13) and DeMeester $(14,15)$ indicated that it is possible to protect this physiological functions by preserving of the vagal plexus. Further, in latest articles, preservation of vagal nerves is recommended in terms of the advantages of a vagal-sparing procedure over a standard esophagectomy for patients with end-stage benign disease and Barrett's high-grade dysplasia or intramucosal adenocarcinoma (16-18). Our aim was to avoid the postoperative complication of vagatomy; therefore, we performed VSE. The patient was put on early liquid enteral nutrition, and during her early postoperative monitoring, the patient did not suffer from the arduous classical post-vagatomic complications (dumping, diarrhea, gastric stasis, etc.) until her suicide attempt. Unfortunately, we were not able to observe long-term outcomes of the surgery because of sudden suicidal death of the patient.

The preservability of the vagal nerves and the esophageal plexus with esophageal stripping technique was particularly emphasized by Banki et al. (1). Their study demonstrated that VSE had better results in terms of gastric secretion, gastric emptying, meal capacity, and body mass index when compared with standard esophagectomy. This procedure allowed the patients to eat a normal meal, free of dumping or diarrhea.

Traditional anatomy textbooks described mediastinal portions of vagal nerves composing a plexus around the esophagus. However, Herbella et al. (19) identified four patterns of vagal trunks in their cadaveric study. Two distinct trunks without communicating branches, present in $26.7 \%$ (type 1) and two crossing trunks in 3.3\% (type 4). The two other vagi patterns include two trunks communicating with a plexus $(56.7 \%)$, which were classified as type 2 , and one or more bifurcated trunks (13.3\%), classified as type 3. The authors reported that VSE was feasible in all cases. Nevertheless, the study was conducted on cadavers; therefore, it could be much more difficult to perform such surgery in patients with type 2 or 3 anatomical variation of vagi. However, in $30 \%$ of all cases, there are only two vagal trunks and no esophageal plexus. In this manner, in $30 \%$ of all cases, it would beeasier to preserve the vagal nerves. In patients with type 1 and 4 intramediastinal vagal anatomy, the vagi should be preserved during esophagectomy to avoid post-vagatomic syndromes. 
Regarding the literature, in most of the studies about vagal preservation, patients undergo open surgery. In contrast, minimally invasive thoracoscopic surgery is associated with significantly less blood loss, reduced postoperative pain and pulmonary complication, increased respiratory function, diminished risk of chylothorax, and shortened length of hospital stay (2022). Likewise, thoracoscopic procedure offers to the surgeon a closer wide range of sight with its magnification, which cannot be obtained even during the exploration with standard thoracotomy (20).Furthermore, a combination of thoracoscopy and laparoscopy could be performed in these patients. In our case, for esophagectomy, we chose the minimally invasive approach instead of thoracotomy. Accordingly, we could remove the apical thorax tube of the patient on the $4^{\text {th }}$ day. Her daily pulmonary auscultations after surgery showed no major abnormality, she did not suffer from major pain, and her respiratory function was good.

Nowadays, an increasing trend in surgery, minimally invasive esophagectomy, might be applicable as an alternative procedure to conventional esophagectomy in patients, especially with end-stage benign disease $(8,9)$. Also, it is possible to spare the vagal nerves by a thoracoscopic approach with a careful dissection, which is a more physiologic alternative. In case of benign or early-malignant lesions, there is no need of nodal or en-block dissection, which make the thoracoscopic VSE an ideal operative technique for these patients.

\section{CONCLUSION}

Although the surgical approach must be chosen according to the patient, it is evident that thoracoscopic VSE is applicable and an alternative procedure to conventional esophagectomy in patients with end-stage benign disease. For now, because of the insufficient series of patients with end-stage caustic stricture, the technical possibility of this procedure is just a proposal. Regarding to our case, if a conventional esophagectomy is planned for a patient with a benign esophageal disease, vagal-sparing thoracoscopic esophagectomy can also be chosen instead of the standard procedures.

Informed Consent: Written informed consent was obtained from patient who participated in this case.

Peer-review: Externally peer-reviewed.

Author Contributions: Concept - D.T., O.A.; Design - D.T., T.M., T.Ç., O.A.; Supervision - O.A.; Resource - F.A., O.A.; Materials - O.A.; Data Collection and/or Processing - D.T., T.M., T.Ç.; Analysis and/or Interpretation - D.T., F.A., O.A.; Literature Search - D.T., O.A.; Writing Manuscript - D.T.; Critical Reviews - O.A.; Other - T.M., T.Ç., F.A.

Conflict of Interest: No conflict of interest was declared by the authors.

Financial Disclosure: The authors declared that this study has received no financial support.

\section{REFERENCES}

1. Banki F, Mason RJ, DeMeester SR, Hagen JA, Balaji NS, Crookes PF, et al. Vagal-sparing esophagectomy: a more physiologic alternative. Ann Surg 2002; 236: 324-335. [CrossRef]
2. Akiyama $H$, Tsurumaru M, Kawamura T, Ono Y. Esophageal stripping with preservation of the vagus nerve. Int Sur 1982; 67: 125-128.

3. Collard JM, Romagnoli R, Goncette L, Gutschow C. Whole stomach with antro-pyloric nerve preservation as an esophageal substitute: an original technique. Dis Esophagus 2004; 17: 164-167. [CrossRef]

4. Boliukh BA, Tkach AA. Actuality of the vagus nerve preservation during esophagectomy for esophageal cancer. Klin Khir 2006; 59-61.

5. Wang GF, Zhang BJ, Yang WF, Wang SP, Shen HM, Yu SJ. Study of gastric function after esophagectomy and cardiectomy with vagus nervepreserved and reconstruction of gastric funds in patients with esophageal and cardiac cancer. Zhonghua Wei Chang Wai Ke Za Zhi 2006; 9: 41-45.

6. Gutschow CA, Schröder W, Wolfgarten E, Hölscher AH. Merendino procedure with preservation of the vagus for early carcinoma of the gastroesophageal junction. Zentralbl Chir 2004; 129: 276281. [CrossRef]

7. Knežević JD, Radovanović NS, Simić AP, Kotarac MM, Skrobić OM, Konstantinović VD, et al. Colon interposition in the treatment of esophageal caustic strictures: 40 years of experience. Dis Esophagus 2007; 20: 530-534. [CrossRef]

8. Dieter RA Jr. Thoracoscopic esophageal surgery. Int Surg 1997; 82: 119-122.

9. Nguyen NT, Roberts P, Follette DM, Rivers R, Wolfe BM. Thoracoscopic and laparoscopic esophagectomy for benign and malignant disease: lessons learned from 46 consecutive procedures. J Am Coll Surg 2003; 197: 902-913. [CrossRef]

10. Ramasamy K, Gumaste VV. Corrosive ingestion in adults. J Clin Gastroenterol 2003; 37: 119-124. [CrossRef]

11. Zargar SA, Kochhar R, Nagi B, Mehta S, Mehta SK. Ingestion of corrosive acids. Spectrum of injury to upper gastrointestinal tract and natural history. Gastroenterology 1989; 97: 702-707. [CrossRef]

12. Rajan R, Rajan R, Rajan N, Pai US. Gastric pull-up by eversion stripping of oesophagus. J Laryngol Otol 1993; 107: 1021-1024. [CrossRef]

13. Chang EY, Jobe BA. Vagal-sparing esophagectomy. J Op Tech Gen Surg 2006; 1053: 136-149. [CrossRef]

14. DeMeester SR. Endoscopic mucosal resection and vagal-sparing esophagectomy for high-grade dysplasia and adenocarcinoma of the esophagus. Semin Thorac Cardiovasc Surg 2005; 17: 320325. [CrossRef]

15. DeMeester SR. Vagal-sparing esophagectomy: is it a useful addition? Ann Thorac Surg 2010; 89: S2156- S2158. [CrossRef]

16. Peyre CG, DeMeester SR, Rizzetto C, Bansal N, Tang AL, Ayazi S, et al. Vagal-sparing esophagectomy: the ideal operation for intramucosal adenocarcinoma and barrett with high-grade dysplasia. Ann Surg 2007; 246: 665-671. [CrossRef]

17. Peyre CG, DeMeester TR. Vagal-sparing esophagectomy. Adv Surg 2008; 42: 109-116. [CrossRef]

18. Splittgerber M, Velanovich V. Barrett esophagus. Surg Clin North Am 2015; 95: 593-604. [CrossRef]

19. Herbella FA, Regatieri CV, Moreno DG, Matone J, Del Grande JC. Vagal integrity in vagal-sparing esophagectomy: a cadaveric study. Dis Esophagus 2006; 19: 406-409. [CrossRef]

20. Mao T, Fang W, Gu Z, Guo X, Ji C, Chen W. Comparison of perioperative outcomes between open and minimally invasiveesophagectomy for esophageal cancer. Thorac Cancer 2015; 6: 303-306. [CrossRef]

21. Yang J, Lyu B, Zhu W, Chen J, He J, Tang S. A retrospective cohort comparison of esophageal carcinoma between thoracoscopic and laparoscopic esophagectomy and open esophagectomy. Zhonghua Wai Ke Za Zhi 2015; 53: 378-381.

22. Kinjo $Y$, Kurita N, Nakamura F, Okabe H, Tanaka E, Kataoka $Y$, et al. Effectiveness of combined thoracoscopic-laparoscopic esophagectomy:comparison of postoperative complications and midterm oncological outcomes in patients with esophageal cancer. Surg Endosc 2012; 26: 381-390.[CrossRef] 